\title{
Review
}

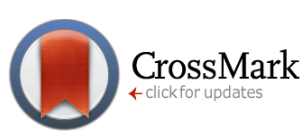

\section{Hearing impairments, presbycusis and the possible therapeutic interventions}

\section{Basharat Hussain 1, Muhammad Ali2, Muhammad Qasim ${ }^{1}$, Muhammad Shareef Masoud', Luqman Khan ${ }^{2,3, *}$}

\author{
1Department of Bioinformatics and Biotechnology, Government College University \\ Faisalabad, Pakistan \\ 2Department of Zoology, Government College University Faisalabad, Pakistan \\ ${ }^{3}$ Division of Neurogenetics, Graduate School of Life Sciences, Tohoku University, Japan
}

\section{Abstract}

*For correspondence:

luqman.zoology@gmail.com

Competing interests: The authors declare that no competing interests exist.

Received: 15 March 2017

Accepted: 02 April 2017

Published: 20 April 2017

Copyright The Author(s) 2017. This article is published with open access by BioMedPress (BMP).

This article is distributed under the terms of the Creative Commons Attribution License (CC-BY 4.0) which permits any use, distribution, and reproduction in any medium, provided the original author(s) and the source are credited.
The hearing is an important sensation of all living organism to maintain his or her life mainly in human. Any distortion to it leads to hearing impairment. Hearing loss (HL) can be congenital or acquired. It can be syndromic; $\mathrm{HL}$ associated with other abnormalities or non-syndromic, $\mathrm{HL}$ is not associated with any other anomalies. Hearing impairment have mostly autosomal recessive loci, but can be autosomal dominant, X-linked, and mitochondrial. Acquired HL can be genetic or environmental factors based. Agerelated $\mathrm{HL}$ is acquired hearing loss occur in aged population. Its prevalence rate increases with age. Genetic of presbycusis is not well-known, but NAT2*6A polymorphism, SNPs in KCNQ4, grainy head-like 2 gene, Glutamate receptor-7 gene, 4977-bp mt-DNA deletion in human and 4834-bp mtDNA deletion in rodents were identified. Different strains of mice are developed like C57BL/6J, CBA/CaJ, DBA/2J, BALB/cJ and Fisher 344 albino rats mainly used as models to study $\mathrm{HL}$ and presbycusis. Like other disorders have complete treatment, but $\mathrm{HL}$ cannot be completely treated. However some attempts can be made for its betterment by using hearing aid devices, surgical and pharmaceutical treatments. In future stem cells and gene therapy will be the affective methods to treat congenital hearing impairment and presbycusis.

\section{Keywords}

Hearing Loss, Prevalence, Factors, Presbycusis Genetics, Animal models, Treatments 


\section{Introduction}

Hearing is the process through which all living organisms understand different sound waves and respond according to it. It has significant contribution in human life, as it maintain the safety and wellness of human beings. Like if someone has good sense of hearing, crossing road he/she will be safe otherwise become a victim of road accident. Ear is an important organ of hearing. It has three parts, the outer, middle and the inner ear. Any defects in these parts lead to hearing loss. Hearing loss is the partial or total inability of either single or both ears to hear. Hearing impairment deteriorates the quality of human life. Affected persons become socially isolated from their society (Martin, 2003).

Hearing loss has different classification based on different criteria like based on severity it can be mild, moderate, severe and profound. It can be conductive, sensorineural and mixed based on defects in different portions of the ear. Hearing impairment can be congenital (prelingual) or acquired (post-lingual). It can be syndromic (30\%) or nonsyndromic (70\%) (Schrijver, 2004). The nonsyndromic $\mathrm{HL}$ can be autosomal dominant (DFNA), autosomal recessive (DFNB), X-linked (DFN) and mitochondrial (Smith et al., 2005).

Presbycusis is acquired hearing loss which progresses with the age, also called age-related hearing loss (AHL). In elderly group the incidence of various disabilities related to age is known to be high. The aged people rely on hearing to face these disabilities. In both elders' and youngers' hearing is an important sensation (Zhang et al., 2013). If hearing sense of aged people is good their quality of life will be good. In contrast, if the elderly group becomes a victim of hearing loss, then their life quality would be substantially reduced and contributes to depression, social isolation and possibly dementia in the elderly (Woodcock \& Pole, 2008). Age-related hearing loss (Presbycusis) is a progressive bilateral symmetrical sensorineural hearing loss result from aging (Zhang et al., 2013). Presbycusis is describe as; patient in noisy environment cannot understand speech, cannot locate sound sources, his/her acoustic information central process become slowed and hence his/her hearing deteriorated (Gates and Mills, 2005; Zhang et al., 2013). It can be sensory, metabolic or neural depends on parts of the ear to be damaged (Mills et al., 2006; Schuknecht and Gacek, 1993).

Different factors are involved to cause presbycusis, can be intrinsic (genetic) or extrinsic (environmental) (Zhang et al., 2013). It occurs in elder people having age 60s or over 70s (Woodcock and Pole, 2008). Approximately 30\% of elder people suffer from presbyscusis (Corna et al., 2009). The Center for Disease Control (U.S), reported in 2003 that in aged population next to arthritis, agerelated hearing loss was the second most common disorder (Schuknecht and Gacek, 1993; Zhang et al., 2013). Presbycusis along with the cognitive, emotional and physical activities also affects the social functioning of the patients. Hence due to various symptoms such as lowered self-esteem, 
depression and social isolation the life of patients deteriorated (Wallhagen et al., 1997).

Approximately ten mutant genes, gene modifiers and mtDNA mutations have been discovered (Van Eyken et al., 2007). Different strains of mice have been developed for the study of congenital and acquired hearing loss. Although the treatment of hearing loss is not completely understood, but can be managed by cochlear implant, use of hearing aid device (Huang and Tang, 2010), pharmaceuticals (Salami et al., 2010). Stem cells and gene therapy (Tadros et al., 2008) are the future treatment that can recover acquired and congenital hearing loss (Ito et al., 2001). To study hearing process and its disorder, causing factors are too much necessary, as it leads towards its therapeutic intervention. I studied multiple research and review articles but included those, have pathophysiology, prevalence, causing factors, genetics, and treatment of mainly age-related hearing loss.

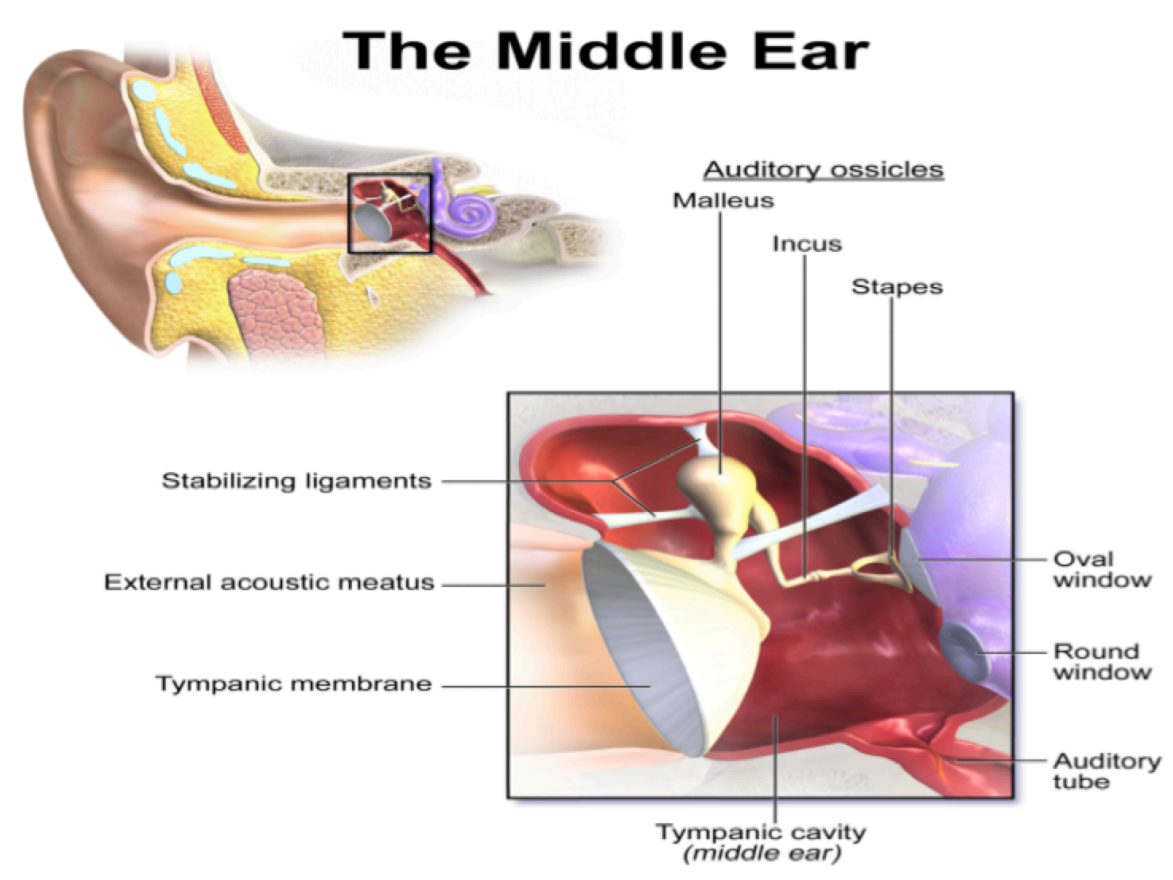

Figure 1. Anatomy of Middle Ear. It starts from tympanic membranes that transfer sound energy into vibrational energy, then ossicles (malleus, incus, and stapes) bones that convert vibrational energy into mechanical energy (Hudspeth, 1989).

\section{Anatomy and Physiology of the Ear}

The most important sensation to the people of the World, which maintains their safety and wellness and promotes their quality of life, is hearing. One of the 
important organs of the human body is ear. It plays a very important role in their life by hearing different sound waves. The human ear has three parts, the outer, the middle and the inner ear. The outer ear consists of the auricle or pinna and the ear canal (external auditory meatus). The middle ear includes eardrum and three small bones malleus, incus and stapes, which are, assembled together, the ossicles as shown in Fig. 1 (Martin, 2003).

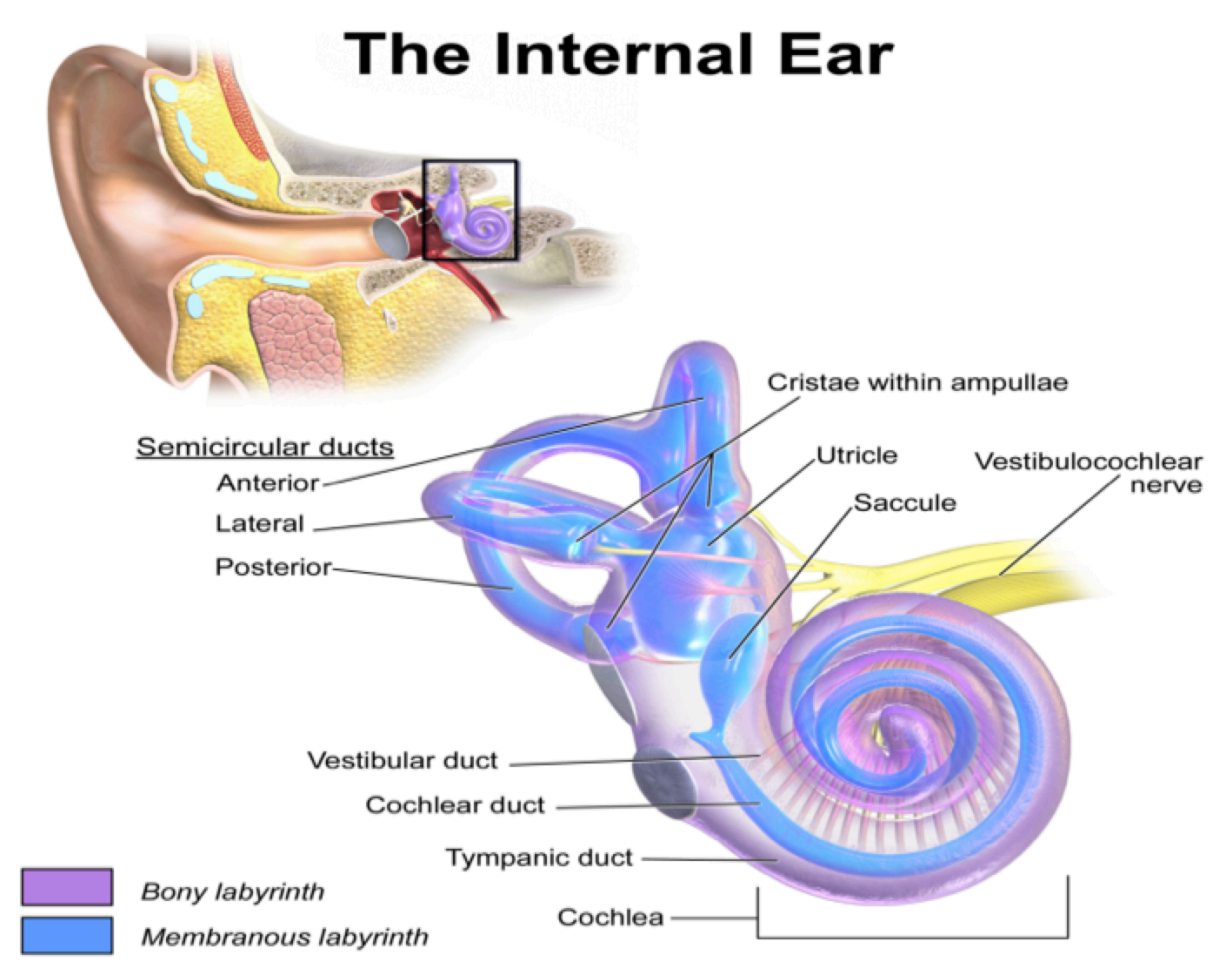

Figure 2. Anatomy of Inner Ear. It consists of six mechanoreceptor structures: three semicircular ducts, utricle, saccule, and the cochlea. The bony labyrinth has continuous stone like cavities along with the temporal bone while membranous labyrinth is present within the bony labyrinth that is a series of communicating ducts and sacs. These portions have role in sensation and balance (Hudspeth, 1989).

These bones connect the outer ear with the inner ear. The inner ear comprises of the semi-circular canal (vestibule), the cochlea and the cochlear nerves as shown in Fig. 2. Hair cells reside in inner ear, which is the sensory portion of the ear. From the environment, the outer ear pinna collects different sound waves, which passes through the ear canal and reaches the tympanic membrane (eardrum), it starts vibrations. The middle ear bones move like a pistol due to these vibrations, which will lead to the movement of the sensory portion of the ear that is fluids inside the inner ear (Martin, 2003). The human inner is a highly complicated organ composed of a cochlear duct responsible for hearing and 
vestibular portion for balance. When sound energy and balance information reaches the cochlea, the hair cells convert it into electrical signals, which are then transmitted to the brain through their associated neurons hence result to understand the sound waves and responded to balance information's. The inner ear hair cells development is a result of a series of differentiation and cell fate decision process which are tightly regulated by a combination of extrinsic and intrinsic factors (Kelley, 2006). Various causes can be easily damaged these hair cells including genetic mutations, aging, drugs and noise. In most cases the damage is irreversible, lead to permanent hearing loss (Dror and Avraham, 2009). In this regards efforts using gene therapy or stem cells have met with only limited success to regenerate or preserve these hair cells (Izumikawa et al., 2005; Li et al., 2003a; Oshima et al., 2010). Normal hair cells development better understanding may help to overcome such limitations.

\section{Classification of Hearing Loss}

In developing countries, $\mathrm{HL}$ is a major public health concern which rate is two thirds of the worldwide HL patients (Tucci et al., 2010). HL can be classified into different criteria involve based on severity, $\mathrm{HL}$ can be classified as; mild: 20 to 39 $\mathrm{dB}$, moderate: 40 to $69 \mathrm{~dB}$, severe: 70 to $89 \mathrm{~dB}$, or profound: $\geq 90 \mathrm{~dB}$, based on age of onset as; congenital (pre-lingual) or acquired (post-lingual), based on affected portion of the ear as; conductive, sensorineural or mixed and based on associated or not with abnormalities in other parts of the body as; syndromic or nonsyndromic (Schrijver, 2004). The genetic basis of pre-lingual HL is estimated to be at least $50 \%$ and for nonsyndromic hearing loss (NSHL) it is $70 \%$, whereas the remaining $30 \%$ are syndromic. Over 400 syndromic forms have been described till to now; the most common examples are; Pendred syndrome and Usher syndrome (Hilgert et al., 2009). The nonsyndromic HL have different mode of inheritance; can be autosomal dominant (DFNA) comprises $\sim 20 \%$, can be autosomal recessive (DFNB) encompasses $\sim 80 \%$ of cases, can be X-linked (DFN) transmit $\sim 1 \%$ cases or can be mitochondrial comprises $<1 \%$ cases. The autosomal recessive nonsyndromic hearing loss (ARNSHL) prevalence frequency is even greater in countries have high rate of consanguineous marriage (Smith et al., 2005). It is estimated that up to $1 \%$ of human genome is to be involved in auditory process. For NSHL over 130 loci have been identified and is clinically and genetically heterogeneous disorder (Hilgert et al., 2009), of which more than 70 DFNB loci have been identified for ARNSHL (Smith et al., 2014).

\section{Presbycusis}

In Greek, Presbycusis means old and hearing (Zwaardemaker, 1891). In aged population it is very common. In various studies it is investigated that hearing impairment $(\mathrm{HI})$ is associated with multiple factors, among older adults age is the 
main factor with the highest epidemiology rate (Wallhagen et al., 1997; Yueh et al., 2003).

Based on etiology, Presbycusis have been divided into three subtypes.

I. Sensory Presbycusis; its causing factor is noise which permanently distort and degenerate the hair cells of the cochlea.

II. Strial or metabolic presbycusis; is due to the decline in the cochlea metabolic function.

III. Neural Presbycusis; in this the degeneration of the auditory nerve occurs (Mills et al., 2006; Schuknecht and Gacek, 1993).

However, in the prevalence of Presbycusis, gene-associated hereditary susceptibility has been observed to play an important role (Rodriguez-Paris et al., 2008; Ünal et al., 2005).

\section{Factors of Presbycusis}

There are mainly two factor involved in age-related hearing loss:

\section{Intrinsic factors}

It included genetic disorders such as Ahl, mutation in mitochondrial DNA, systemic diseases such as sickle cell anemia, metabolic disease and diabetes.

\section{Extrinsic factors}

It involved ototoxic medication, diet and noise. Both factors cannot separated from each other (Schuknecht and Gacek, 1993; Zhang et al., 2013).

The aging process contributed to different changes in the body, which may be physiological, molecular, and biochemical. In physiological changes, decreased elasticity of cellular membranes occurs, the molecular changes reduce mitochondrial function, increases in DNA damage and the biochemical changes involved decreases in ionic changes and cellular water concentrations (Prazma et al., 1990; Seidman et al., 1996). In humans the aging process occurs in every organs of the body. The aging process can also occur in the external, middle ear and inner ear. In inner ear, cochlea is the hearing portion consisting of hair cells (Schuknecht and Gacek, 1993). In cochlea aging process occur that leads to loss of hair cells (Nelson and Hinojosa, 2006). The hair cells are very vulnerable as they change sound waves into nerve impulses that are critical to normal hearing function (Zhang and Surles, 2008). The hair cells once degenerated; the degeneration is permanent because in human inner ear cochlea the hair cells live only once. As the eye has eye-lid and eye does not work during sleeping, 
but due to absence of ear lid, it works 24 hours without any rest. It does not depend on that a person is either healthy or not, can develop presbycusis sooner or later due to progressive loss of hair cells (Zhang et al., 2013).

\section{Prevalence}

The epidemiology of presbycusis can be expressed in percentage and the majority of aged population have hearing impairment (Rothman, 2012). Hearing impairment is one of the most common sensory disorders observed in the population. In the US it is estimated that 1 in 1000 people is born deaf or acquired in early childhood (Morton, 1991). But in Pakistan its prevalence is 1.6 in 1000 people (Elahi et al., 1998).

As one of the most important factors of hearing impairment is the aging process (Ryan, 2000). Therefore $10 \%$ of the elderly have age 65 or above, are suffer from hearing loss with the highest prevalence rate in North America (Wallhagen et al., 1997). Hearing impairment occurs in later life either have good or bad sociodemographic factors like education, income and marital status (Corna et al., 2009). The results of age-related hearing loss prevalence may vary among various literature reports. The American Speech Language Hearing Association statistically reported in aged Americans, hearing loss is the $3^{\text {rd }}$ have high prevalence rate. In older people hearing impairment is the most common communicative disorder, for example hearing loss occurs of about $25 \%$ to $40 \%$ of the population have age 65 or above (Frisina and Walton, 2006; Yueh et al., 2003).

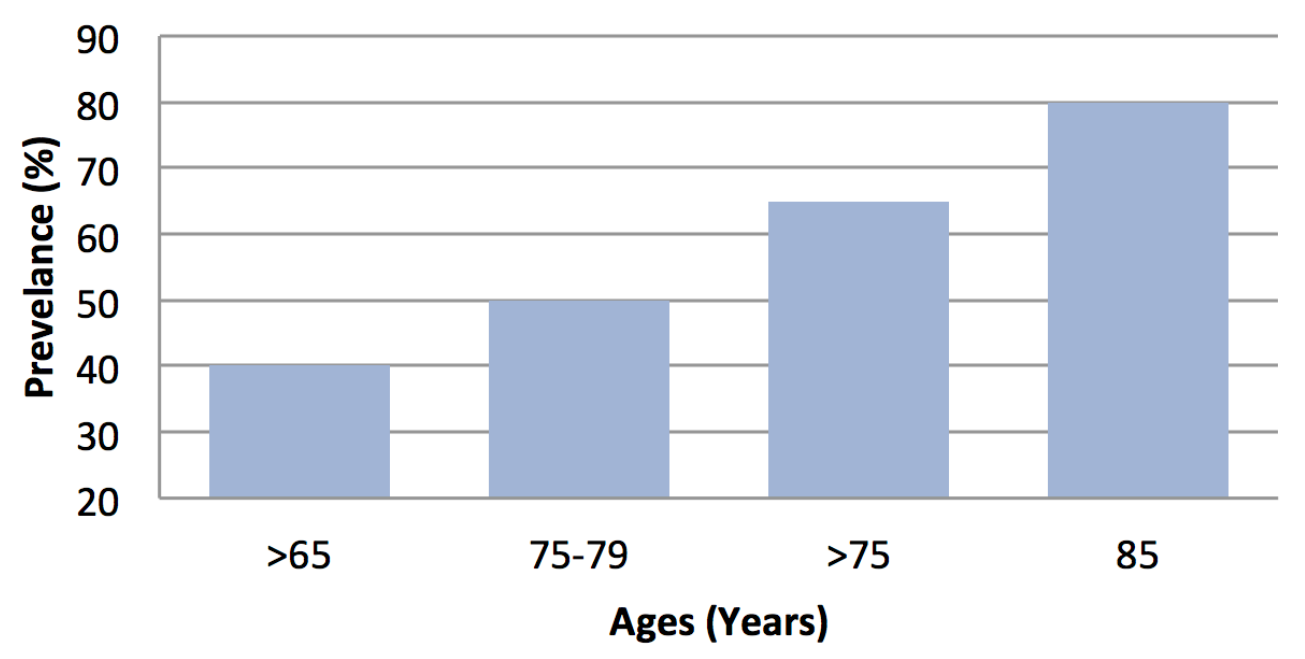

Figure 3. Prevalence of presbycusis as a function of age, it increases with age. In each group, the prevalence of hearing loss shows as percentage of the population (Zhang et al., 2013). 
Like the USA, the Canadian Association of Speech Language Pathologists and Audiologists also confirms the prevalence of hearing loss. It reported $20 \%$ of population are affected have $>65$ years, while $40 \%$ are affected have $>75$ years of age (Zhang et al., 2013). With the age the prevalence rate of hearing impairment will be high. The people have age 70-74 years, its presbycusis prevalence range can be between $25 \%, 50 \%$ at 85 years old, and it can be $>80 \%$ at age of 85 or above (Bogardus Jr et al., 2003; Desai et al., 2001; Yueh et al., 2003) as shown in Fig. 3. Due to this high prevalence rate, presbycusis is one the critical issue in our society.

From different multiple studies, the presbycusis prevalence data obtained are not contradictory, but can be overlapped to each other in terms of progressive rate of presbycusis. As it can be shown in Fig. 3 based literature survey (Corna et al., 2009; Woodcock and Pole, 2008).

The world wide studies of World Health Organization showed that, in 1999, $>120$ million, in 2005, 278 million, and in 2011, 642 million people suffered from hearing loss. The estimation that how many people will be affected by 2017 , 2025 and even by 2031 will be surprising. It is estimated that the percentage of presbycusis prevalence is increase to $21.8 \%$ up to 2031 as shown in Fig. 4 (Brencla, 1997; Carson and Pichora-Fuller, 1997; Secretariat, 1993). Here is a proposed projection which estimated that 1248 million people in 2017, 2568 million people in 2025, and 5136 million people in 2031 will suffered from hearing loss.

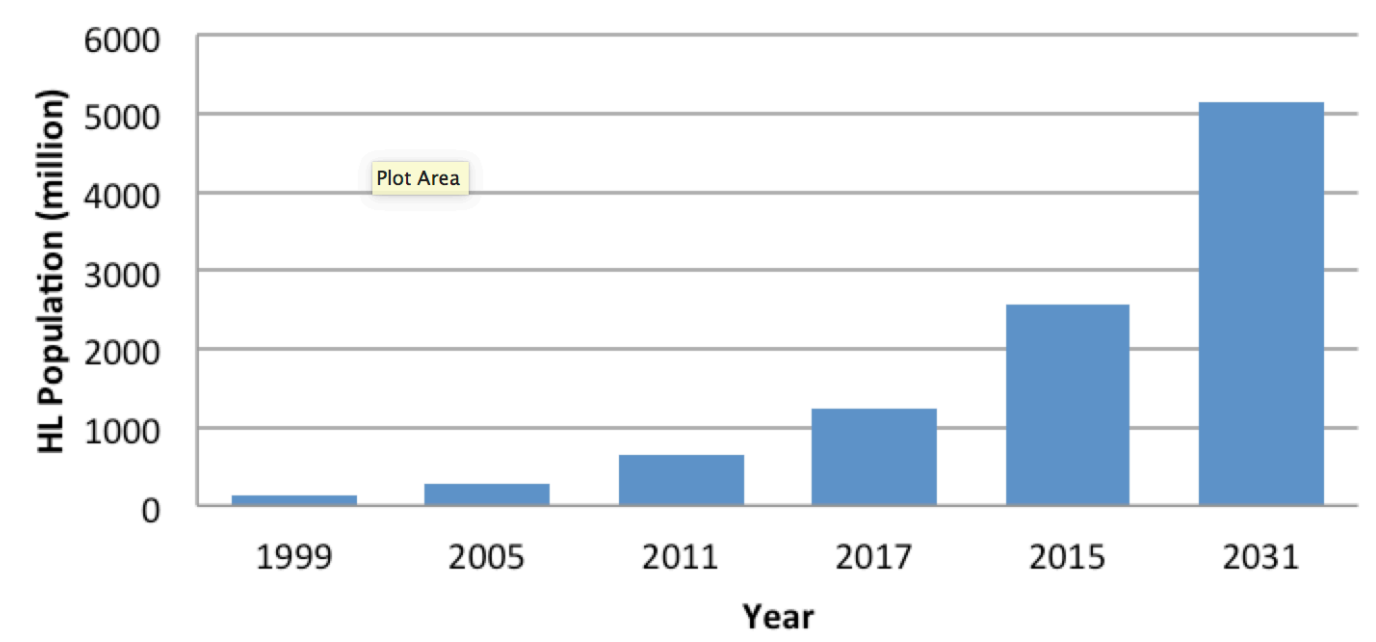

Figure 4. Showed the prevalence of hearing impairment as a function of year, the total number of hearing loss patients worldwide and $\mathrm{HL}$ increase each year (Zhang et al., 2013). 


\section{Genetics of Presbycusis}

Genetic is one of the most critical factors of presbycusis. Different genes contribute to hearing impairments, which lead to Presbycusis. The genes related to presbycusis have been discovered, including gene modifiers, ten presbycusis genes and mitochondrial DNA mutation. Through genome wide studies association age-related hearing loss genes include NAT2*6A polymorphism, SNPs in KCNQ4, common 4977-bp mitochondrial DNA deletion, grainy headlike 2 gene and Glutamate receptor-7 gene were identified (Van Eyken et al., 2007).

In mitochondrial respiratory chain the ATP is generated by oxidative phosphorylation, but due to mitochondrial dysfunction which affect oxygen free radical, apoptosis and calcium imbalance, leads to hearing loss. The mtDNA mutation in mice showed early presbycusis (Niu et al., 2007). In human mtDNA 4977 mutation related to presbycusis and mtDNA 4834 in rodents (Lee, 2013).

\section{Animal Models Used to Study Presbycusis}

It is explored that 19 inbred strains of mice model have presbycusis (Johnson et al., 2003; Johnson et al., 2008; Johnson et al., 2006). Out of these, 10 strains had age-related hearing loss (Ahl) locus on chromosome 10 (Johnson et al., 2000). Ahl is a core gene in C57BL/6J mice as it encodes cadherin-23 and for presbycusis. C57BL/6J mice were used as a key model because they exhibited at age of 6 months high frequency hearing loss. At age of 12 months, lowfrequency hearing loss and at age of 15 months, whole frequency hearing loss was observed (Fetoni et al., 2011). In the cochlea histological changes occur due to the progression of hearing impairment. In C57BL/6J, the degeneration of the abaxial cochlea neurons have association with the degeneration of peripheral hair cells as both leads to presbycusis (Idrizbegovic et al., 2001). In C57 mice in addition to early presbycusis, in the nucleus of ventral cochlea changes in sensitivity were also observed, as for the analysis of sound features like temporal cue, frequency and sound intensity in the central hearing system, the cochlear nucleus is responsible (Caspary et al., 2008). Another animal model CBA/J mouse was developed, in this model, Ahl resistance alleles such as Ahl 2, Ahl 4 and Ahl 8 were also explored in addition to Ahl, Ahl 3. Ahl resistant allele was discovered in CBA/J mice model and has observed at age of 12 months, developed high-tone hearing impairment. It was investigated at age of 18 months that the mice model has to begin the outer hair cells loss, and also observed until the age of 25 months that the model did not develop any abnormality in stria vascularis. For neural and sensory presbycusis therefore these are used as models (Sha et al., 2008). Another model CBA/CaJ mice was developed and widely used as a model for strial and metabolic presbycusis. As it was observed that this model has hearing impairment early with declined endocochlear potential. DBA/2J mice used as a model and shown loss of 
cochlear ganglion and outer hair cells at age of two months led to hearing loss. Ahl genes were also present in this model (Fetoni et al., 2011). A model BALB/cJ mice for metabolic presbycusis was observed at age of 19 months to have a decrease in endocochlear potential and presbycusis (Popelar et al., 2006). At age of 12 months, Fisher 344 albino rats developed a rapid presbycusis due to degeneration of stria vascularis and outer hair cells (Fetoni et al., 2011; Popelar et al., 2006). It has been studied in Fischer 344 rats, the aging process lost the glycinergic inhibition in the nucleus of ventral cochlea. It also changed the dorsal cochlear nucleus coding intensity (Caspary et al., 2008). Mongolian gerbils developed models for metabolic age-related hearing impairment and shared similar pathological characteristics as humans. In these models, inside the gerbils, a decline of endocochlear potential, the atrophy of spinal ligaments and stria vascularis were investigated (Gratton et al., 1997; Mills et al., 1990). Similar to humans, Chinchillas have aged-related hearing loss, but poses a limitation as it has long life span of 20 years, therefore does not use for the studies of presbycusis (Lee, 2013).

\section{Treatment}

As presbycusis is a sensorineural hearing loss, so cannot be cured or prevented and there are no recommended or approved pharmaceutical treatments. However some attempts can be used for its betterment. The attempt options of treatment for presbycusis fall into three categories: surgical, management and pharmacological.

\section{Surgical Treatment}

It involves surgical cochlear implant and is possible in cases of profound or severe hearing loss. A cochlear implant is a complex electronic device that replaces the inner ear cochlea. This device may enable the presbycusis patient to understand the environmental sound and speech waves. But there is a difference between natural hearing sound spectrum and the sound spectrum produces by the cochlear implant (Huang and Tang, 2010).

\section{Management}

It involves hearing aids devices and aural rehabilitation. Hearing aids now help improve the hearing of many aged people and can be tuned to specific frequency ranges of hearing loss. Aural rehabilitation may reduce the impact on communication between the affected person and their communication partners. It includes different techniques like reduce environmental noise, communicates directly, pronounced clearly with the affected person and used of contextual signs to improve comprehension (Huang and Tang, 2010).

\section{Pharmaceuticals}


Until now the pharmaceutical treatment for presbycusis remain limited and clinically unproven. The limited treatments for age-related hearing loss are: water-soluble coenzyme Q10 (CoQ10) formulation, the prescription drug Tanakan, and combination antioxidant therapy. In 2010 it was explored that coenzyme Q10 a water-soluble formulation improved the air laminar tonal audiometry and bone thresholds at $1000 \mathrm{~Hz}, 2000 \mathrm{~Hz}, 4000 \mathrm{~Hz}$, and $8000 \mathrm{~Hz}$ (Salami et al., 2010). Coenzyme $\mathrm{Q} 10$ has antioxidant properties similar to a vitamin. It produces in the body, but with the age its levels fall (Yamasoba et al., 2013).

Tanakan is a vasodilator and is an international brand name of prescribed drug extract of Ginkgo biloba. Its pharmaceutical effects were observed when treating aged women with tympanophonia. It was found that Tanakan improved hearing and speech in adult patients, decreases tympanitis intensity, and gives idea to recommend the presbycusis treatment (Boboshko et al., 2010). Antioxidant therapy is a combination of six antioxidant agents, i.e. ribose-cysteine, Lcysteine-glutathione mixed disulfide, NW-nitro-L-arginine methyl ester, folate, vitamin B12, and vitamin C, within the oxidative pathway it target four sites (Boboshko et al., 2010).

Ebselen is a synthetic drug molecule composed of organic selenium with antioxidant, anti-inflammatory and cytoprotective activity (Schewe, 1995). It mimics glutathione peroxidase (GPx), a crucial enzyme that protects the inner ear from damage caused by noise or loud sounds (Dudbridge, 2008). It is found that ebselen can be used as a possible treatment for hearing loss and tinnitus (Kil et al., 2007).

\section{Treatment in Future}

\section{Transplant therapy of stem cells}

It has been investigated in vitro that the mature central nervous system does have the potential to regenerate nerve. In this observation scientists successively in vitro departed neural stem cells from various sites of brains of human and mammals. It was demonstrated in a research carried out by lto (Ito et al., 2001) that cochlea environment is compatible to the stem cells of neurons. Kojima explored that immature progenitors neurons have the potential to differentiate into the phenotypes of hair cells (Kojima et al., 2004). This research gives hope to treat the damaged cochlea and presbycusis. In animal models such as guinea pig or murine, it has been reported that embryonic stem cells (Li et al., 2003b) or progenitor cells (Rivolta et al., 2006), the adult utricular sensory epithelium stem cells (Li et al., 2003a), and even stem cells of marrow (Ge et al., 2005) also have some potential to differentiate into audiometric cells. These researches help us to remedy age-related hearing impairment patients at the cell replaced therapy level with neural stem cells, xenogeneic or autologous embryonic stem cells, and 
even the stem cells of marrow. This treatment is still limited to animal models and theory. For human application this technology remains years or even decade's away.

\section{Gene therapy}

For gene therapy various number of administration routes have been suggested. It has been investigated that the apoptosis of related cells due to gene mutation, aging and ototoxic medications is the final way to cause deafness. In aged gerbil cochlea that the bcl-2 protein expression is suppressed due to activation of caspase-3, leads to apoptosis induced presbycusis (Alam et al., 2001). Matsui found that after the treatment of amino glycoside to inhibit the caspases activation promotes the hair cells survival (Matsui et al., 2003). These results showed that to activate the apoptosis inhibitors like caspase- 3 may provide protection to presbycusis related cells. Tandros had observed that in inner ear aging 31 genes play important roles. The genes include are: B cell leukemia/lymphoma 2, activating transcription factor 3, Calpain2, Bcl2-like1, tumor necrosis factor receptor superfamily member 12 a, tumor necrosis factor superfamily member $13 \mathrm{~b}$, caspase 4 apoptosis-related cysteine protease 4 , dual specificity phosphatase 9 (Tadros et al., 2008). Thus, the apoptosis related genes should be the candidate gene for gene therapy. Beside the apoptosis related genes, in the past few years, the cell cycle regulatory genes (Chen et al., 2003a; Löwenheim et al., 1999; Mantela et al., 2005), neurotrophin-based gene (Chen et al., 2003b) and cellular and functional restoration gene (Izumikawa et al., 2005) were so much promising and hot fields of gene therapy.

\section{Suggestions}

- Different research should be conducted to determine the actual cause and frequency prevalence of hearing loss in the country.

- The information's resulted from these research should develop different strategies to help people with hearing impairment.

- The society should be well aware about the etiology of hearing loss.

- If the disorder is due to genetics then the families should be well aware to avoid consanguineous marriages.

- To remove the psychological problems there should be no social discrimination among people with hearing disorder.

- The health care providers at hospitals and audiology clinics should be well trained about hearing loss. 
- The people with hearing loss should wear hearing aid device to protect himself from road accident.

- To aid the people with hearing loss the government should develop different programs, which can encourage the community to be self-supported

\section{Conclusion}

Hearing impairment is the most common neurosensory defect in human. In developing countries it is two-third of worldwide hearing loss. Genetic basis of congenital hearing loss is $50 \%$, nonsyndromic hearing loss is $70 \%$, and remaining $30 \%$ is syndromic. Pendred syndrome and Usher syndrome are common examples of syndromic hearing loss. The non-syndromic HL have different mode of inheritance; can be autosomal dominant (DFNA) comprises $\sim 20 \%$, can be autosomal recessive (DFNB) encompasses $\sim 80 \%$ of cases, can be X-linked (DFN) transmit $\sim 1 \%$ cases or can be mitochondrial comprises $<1 \%$ cases. The autosomal recessive non-syndromic hearing loss (ARNSHL) prevalence frequency is even greater in countries have high rate of consanguineous marriage. It is estimated that up to $1 \%$ of human genome is to be involved in auditory process. For NSHL over 130 loci have been identified and is clinically and genetically heterogeneous disorder of which more than 70 DFNB loci have been identified for ARNSHL. The population above 40 years of age in those countries where the average age is 50 years and have hearing loss called presbycusis. As the people become aged with the passage of time, and the ratio of $A H L$ in the aged people become higher and higher. Presbycusis can be due to environmental or genetic factor. Some genetic mutations related to presbycusis have been identified. It is important to give awareness to the affected family to avoid consanguineous marriages, to prevent their future family members from hearing impairments. It is also very important and clinically significant to develop and identify therapeutics treatments, potential protective measures to avoid presbycusis and $\mathrm{HL}$. The above all reported treatment is still limited to animal models and the scientists continue their efforts to apply gene therapy to human beings. In future, we assure that due to the development in technology, scientists' efforts and interest that the stem cell and gene therapy will be proved helpful and fruitful to be effectively applied in clinic to cure presbycusis patients. Here the variety of techniques are reviewed by using animal models is the future of therapeutics treatment development. But for human clinical applications best results, these techniques are going to refine and evaluate. In near future the presbycusis might not be completely cured, but can be minimized and prevented. 


\section{Biomedical Research \& Therapy}

ISSN: $2198-4093$

www.bmrat.org

\section{Abbreviations}

AHL: Age-related Hearing Loss; ARNSNL: Autosomal recessive non-syndromic hearing loss; ATP: Adenosine Triphosphate; DFN: Non-syndromic, X-linked deafness; DFNA: Non-syndromic, autosomal dominant deafness; DFNB: Non-syndromic, autosomal recessive deafness; HI: Hearing Impairment; HL: Hearing Loss; KCNO4: Potassium Voltage-Gated Channel subfamily Q Member 4; mt-DNA: mitochondrial DNA; NAT2*6A: $\mathrm{N}$-acetyltransferase 2 Polymorphism; NSHL: Non-syndromic Hearing loss; SNPs Single Nucleotide polymorphisms

\section{Author Contribution}

All authors contributed to the Manuscript. BH collected data and wrote the manuscript. $M A, M Q$, \& MSM edited the first draft. LK contribute to the design and revising the manuscript. All authors reviewed and commented on final draft. 


\section{References}

Alam, S.A., Oshima, T., Suzuki, M., Kawase, T., Takasaka, T., and Ikeda, K. (2001). The Expression of Apoptosis-Related Proteins in the Aged Cochlea of Mongolian Gerbils. The Laryngoscope 111, 528-534.

Boboshko, M., Efimova, M., and Savenko, I. (2010). [Modern aspects of diagnosis of presbycusis and its treatment in elderly patients]. Vestnik otorinolaringologii, 23-25.

Bogardus Jr, S.T., Yueh, B., and Shekelle, P.G. (2003). Screening and management of adult hearing loss in primary care: clinical applications. Jama 289, 1986-1990.

Brencla, G. (1997). Resident and staff education within an ecological audiologic rehabilitation program in a home for the aged. Journal of speech - language pathology and audiology 21, 167-173.

Carson, A.J., and Pichora-Fuller, M.K. (1997). Health promotion and audiology: The community-clinic link. Journal - Academy of Rehabilitative Audiology 30, $29-52$.

Caspary, D.M., Ling, L., Turner, J.G., and Hughes, L.F. (2008). Inhibitory neurotransmission, plasticity and aging in the mammalian central auditory system. Journal of Experimental Biology 211, 1781-1791.

Chen, P., Zindy, F., Abdala, C., Liu, F., Li, X., Roussel, M.F., and Segil, N. (2003a). Progressive hearing loss in mice lacking the cyclin-dependent kinase inhibitor Ink4d. Nature cell biology 5, 422-426.

Chen, X., Li, H., Cao, K., Wei, C., and Jin, X. (2003b). [The transduction of neurotrophin-3/GDNF attenuates the SGNC damage in deaf mice]. Zhonghua yi xue za zhi 83, 1517-1520.

Corna, L.M., Wade, T.J., Streiner, D.L., and Cairney, J. (2009). Corrected and uncorrected hearing impairment in older Canadians. Gerontology 55, 468-476.

Desai, M., Pratt, L.A., Lentzner, H., and Robinson, K.N. (2001). Trends in vision and hearing among older Americans. Aging trends (Hyattsville, Md), 1.

Dror, A.A., and Avraham, K.B. (2009). Hearing loss: mechanisms revealed by genetics and cell biology. Annual review of genetics 43, 411-437.

Dudbridge, F. (2008). Likelihood-based association analysis for nuclear families and unrelated subjects with missing genotype data. Human heredity 66, 87-98.

Elahi, M.M., Elahi, F., Elahi, A., and Elahi, S.B. (1998). Paediatric hearing loss in rural Pakistan. Journal of Otolaryngology-Head \& Neck Surgery 27, 348.

Fetoni, A.R., Picciotti, P.M., Paludetti, G., and Troiani, D. (2011). Pathogenesis of presbycusis in animal models: a review. Experimental gerontology 46, 413-425.

Frisina, R.D., and Walton, J.P. (2006). Age-related structural and functional changes in the cochlear nucleus. Hearing research 216, 216-223.

Gates, G.A., and Mills, J.H. (2005). Presbycusis. The Lancet 366, 1111-1120.

Ge, S.-I., Xie, D.-h., Chen, Z.-c., Xiao, Z.-q., and Yang, X.-m. (2005). Feasibility study of marrow stromal cells transplantation into guinea pig cochlea. Journal of Central South University of Technology 12, 313-316.

Gratton, M., Smyth, B., Lam, C., Boettcher, F., and Schmiedt, R. (1997). Decline in the endocochlear potential corresponds to decreased $\mathrm{Na}$, K-ATPase activity in the lateral wall of quiet-aged gerbils. Hearing research 108, 9-16. 
Hilgert, N., Smith, R.J., and Van Camp, G. (2009). Forty-six genes causing nonsyndromic hearing impairment: which ones should be analyzed in DNA diagnostics? Mutation Research/Reviews in Mutation Research 681, 189-196.

Huang, Q., and Tang, J. (2010). Age-related hearing loss or presbycusis. European Archives of Oto-Rhino-Laryngology 267, 1179-1191.

Hudspeth, A.J. (1989). How the ear's works work. Nature 341, 397-404.

Idrizbegovic, E., Viberg, A., Bogdanovic, N., and Canlon, B. (2001). Peripheral cell loss related to calcium binding protein immunocytochemistry in the dorsal cochlear nucleus in CBA/CaJ mice during aging. Audiology and Neurotology 6, 132-139.

Ito, J., Kojima, K., and Kawaguchi, S. (2001). Survival of neural stem cells in the cochlea. Acta oto-laryngologica 121, 140-142.

Izumikawa, M., Minoda, R., Kawamoto, K., Abrashkin, K.A., Swiderski, D.L., Dolan, D.F., Brough, D.E., and Raphael, Y. (2005). Auditory hair cell replacement and hearing improvement by Atoh1 gene therapy in deaf mammals. Nature medicine 11, 271-276.

Johnson, K.R., Gagnon, L.H., Webb, L.S., Peters, L.L., Hawes, N.L., Chang, B., and Zheng, Q.Y. (2003). Mouse models of USH1C and DFNB18: phenotypic and molecular analyses of two new spontaneous mutations of the Ush1c gene. Human molecular genetics 12, 3075-3086.

Johnson, K.R., Longo-Guess, C., Gagnon, L.H., Yu, H., and Zheng, Q.Y. (2008). A locus on distal chromosome 11 (ahl8) and its interaction with Cdh23 ahl underlie the early onset, age-related hearing loss of DBA/2J mice. Genomics 92, 219-225.

Johnson, K.R., Zheng, Q.Y., and Erway, L.C. (2000). A major gene affecting age-related hearing loss is common to at least ten inbred strains of mice. Genomics 70, 171-180.

Johnson, K.R., Zheng, Q.Y., and Noben-Trauth, K. (2006). Strain background effects and genetic modifiers of hearing in mice. Brain research 1091, 79-88.

Kelley, M.W. (2006). Regulation of cell fate in the sensory epithelia of the inner ear. Nature Reviews Neuroscience 7, 837-849.

Kil, J., Pierce, C., Tran, H., Gu, R., and Lynch, E.D. (2007). Ebselen treatment reduces noise induced hearing loss via the mimicry and induction of glutathione peroxidase. Hearing research 226, 44-51.

Kojima, K., Tamura, S., Nishida, A.T., and Ito, J. (2004). Generation of inner ear hair cell immunophenotypes from neurospheres obtained from fetal rat central nervous system in vitro. Acta oto-laryngologica Supplementum, 26-30.

Lee, K.-Y. (2013). Pathophysiology of age-related hearing loss (peripheral and central). Korean journal of audiology 17, 45-49.

Li, H., Liu, H., and Heller, S. (2003a). Pluripotent stem cells from the adult mouse inner ear. Nature medicine 9, 1293-1299.

Li, H., Roblin, G., Liu, H., and Heller, S. (2003b). Generation of hair cells by stepwise differentiation of embryonic stem cells. Proceedings of the National Academy of Sciences 100, 13495-13500.

Löwenheim, H., Furness, D.N., Kil, J., Zinn, C., Gültig, K., Fero, M.L., Frost, D., Gummer, A.W., Roberts, J.M., and Rubel, E.W. (1999). Gene disruption of p27Kip1 allows cell proliferation in the postnatal and adult organ of Corti. Proceedings of the National Academy of Sciences 96, 4084-4088. 
Mantela, J., Jiang, Z., Ylikoski, J., Fritzsch, B., Zacksenhaus, E., and Pirvola, U. (2005). The retinoblastoma gene pathway regulates the postmitotic state of hair cells of the mouse inner ear. Development 132, 2377-2388.

Martin, H. (2003). The auditory system. Neuroanatomy, 191-206.

Matsui, J.I., Haque, A., Huss, D., Messana, E.P., Alosi, J.A., Roberson, D.W., Cotanche, D.A., Dickman, J.D., and Warchol, M.E. (2003). Caspase inhibitors promote vestibular hair cell survival and function after aminoglycoside treatment in vivo. The Journal of neuroscience 23, 6111-6122.

Mills, J.H., Schmiedt, R.A., and Kulish, L.F. (1990). Age-related changes in auditory potentials of Mongolian gerbil. Hearing research 46, 201-210.

Mills, J.H., Schmiedt, R.A., Schulte, B.A., and Dubno, J.R. (2006). Age-related hearing loss: A loss of voltage, not hair cells. Paper presented at: Seminars in Hearing (Copyright@ 2006 by Thieme Medical Publishers, Inc., 333 Seventh Avenue, New York, NY 10001, USA.).

Morton, N. (1991). Genetic epidemiology of hearing impairment. Annals of the New York Academy of Sciences 630, 16-31.

Nelson, E.G., and Hinojosa, R. (2006). Presbycusis: a human temporal bone study of individuals with downward sloping audiometric patterns of hearing loss and review of the literature. The Laryngoscope 116, 1-12.

Niu, X., Trifunovic, A., Larsson, N.-G., and Canlon, B. (2007). Somatic mtDNA mutations cause progressive hearing loss in the mouse. Experimental cell research 313, 3924-3934.

Oshima, K., Shin, K., Diensthuber, M., Peng, A.W., Ricci, A.J., and Heller, S. (2010). Mechanosensitive hair cell-like cells from embryonic and induced pluripotent stem cells. Cell 141, 704-716.

Popelar, J., Groh, D., Pelánová, J., Canlon, B., and Syka, J. (2006). Age-related changes in cochlear and brainstem auditory functions in Fischer 344 rats. Neurobiology of aging $27,490-500$.

Prazma, J., Carrasco, V.N., Butler, B., Waters, G., Anderson, T., and Pillsbury, H.C. (1990). Cochlear microcirculation in young and old gerbils. Archives of Otolaryngology-Head \& Neck Surgery 116, 932-936.

Rivolta, M.N., Li, H., and Heller, S. (2006). Generation of inner ear cell types from embryonic stem cells. Methods in Molecular Biology 330, 71-92.

Rodriguez-Paris, J., Ballay, C., Inserra, M., Stidham, K., Colen, T., Roberson, J., Gardner, P., and Schrijver, I. (2008). Genetic analysis of presbycusis by arrayed primer extension. Annals of Clinical \& Laboratory Science 38, 352-360.

Rothman, K.J. (2012). Epidemiology: an introduction (Oxford University Press).

Ryan, A.F. (2000). Protection of auditory receptors and neurons: evidence for interactive damage. Proceedings of the National Academy of Sciences 97, 6939-6940.

Salami, A., Mora, R., Dellepiane, M., Manini, G., Santomauro, V., Barettini, L., and Guastini, L. (2010). Water-soluble coenzyme Q10 formulation (Q-TER®) in the treatment of presbycusis. Acta oto-laryngologica 130, 1154-1162.

Schewe, T. (1995). Molecular actions of ebselen-an antiinflammatory antioxidant. General Pharmacology: The Vascular System 26, 1153-1169.

Schrijver, I. (2004). Hereditary non-syndromic sensorineural hearing loss: transforming silence to sound. The Journal of molecular diagnostics 6, 275-284. 
Schuknecht, H.F., and Gacek, M.R. (1993). Cochlear pathology in presbycusis. The Annals of otology, rhinology, and laryngology 102, 1-16.

Secretariat, S. (1993). Ageing and Independence: Overview of a National Survey. Minister of National Health and Welfare, Minister of Supply and Services Canada, Ottawa Cat.

Seidman, M.D., Khan, M.J., Dolan, D.F., and Quirk, W.S. (1996). Age-related differences in cochlear microcirculation and auditory brain stem response. Archives of Otolaryngology-Head \& Neck Surgery 122, 1221-1226.

Sha, S.-H., Kanicki, A., Dootz, G., Talaska, A.E., Halsey, K., Dolan, D., Altschuler, R., and Schacht, J. (2008). Age-related auditory pathology in the CBA/J mouse. Hearing research 243, 87-94.

Smith, R.J., Bale, J.F., and White, K.R. (2005). Sensorineural hearing loss in children. The Lancet 365, 879-890.

Smith, R.J., Shearer, A.E., Hildebrand, M.S., and Van Camp, G. (2014). Deafness and hereditary hearing loss overview.

Tadros, S.F., D'Souza, M., Zhu, X., and Frisina, R.D. (2008). Apoptosis-related genes change their expression with age and hearing loss in the mouse cochlea. Apoptosis 13, 1303-1321.

Tucci, D.L., Merson, M.H., and Wilson, B.S. (2010). A summary of the literature on global hearing impairment: current status and priorities for action. Otology \& Neurotology 31, $31-41$

Ünal, M., Tamer, L., Doğruer, Z.N., Yildirim, H., Vayisoğlu, Y., and Çamdeviren, H. (2005). $\mathrm{N}$-acetyltransferase 2 gene polymorphism and presbycusis. The Laryngoscope 115, 2238-2241.

Van Eyken, E., Van Camp, G., and Van Laer, L. (2007). The complexity of age-related hearing impairment: contributing environmental and genetic factors. Audiology and Neurotology 12, 345-358.

Wallhagen, M.I., Strawbridge, W.J., Cohen, R.D., and Kaplan, G.A. (1997). An increasing prevalence of hearing impairment and associated risk factors over three decades of the Alameda County Study. American Journal of Public Health 87, 440-442.

Woodcock, K., and Pole, J.D. (2008). Educational attainment, labour force status and injury: a comparison of Canadians with and without deafness and hearing loss. International Journal of Rehabilitation Research 31, 297-304.

Yamasoba, T., Lin, F.R., Someya, S., Kashio, A., Sakamoto, T., and Kondo, K. (2013). Current concepts in age-related hearing loss: epidemiology and mechanistic pathways. Hearing research 303, 30-38.

Yueh, B., Shapiro, N., MacLean, C.H., and Shekelle, P.G. (2003). Screening and management of adult hearing loss in primary care: scientific review. Jama 289, 1976-1985.

Zhang, M., Gomaa, N., and Ho, A. (2013). Presbycusis: a critical issue in our community.

Zhang, M., and Surles, J.G. (2008). Voltage-dependent outer hair cell stereocilia stiffness at acoustic frequencies. Neuroreport 19, 855-859.

Zwaardemaker, H. (1891). Der Verlust an hohen Tönen mit zunehmendem Alter. European Archives of Oto-Rhino-Laryngology 32, 53-56. 